\title{
ÉTICA Y DERECHO EN LA PROFESIÓN PERIODÍSTICA EN CHILE
}

\author{
Tomás P. Mac Hale \\ Abogado y Periodista \\ Profesor de Ética y Derecho de la Información \\ Universidad Católica y Universidad Finis Terrae
}

Acaba de ser publicado por el Centro de Estudios Públicos de la capital, una entidad de gran importancia académica para la defensa de la sociedad libre, obra en dos volúmenes, de formato mayor, y de más de 1600 páginas. "Los mil días de Allende", compilada por el Director del CEP. Arturo Fontaine Talavera, y por el profesor de la Universidad Diego Portales, Miguel González Pino. Se trata de una antología de textos periodísticos de todo el espectro político que existió en Chile entre 1970 y 1973, más un substancioso anexo documental.

La obra abarca un completo panorama de la prensa nacional durante un período clave de nuestro desenvolvimiento histórico, durante el cual la comunicación social tuvo graves problemas. Ellos están hoy olvidados por muchos - no en vano han pasado más de 25 años desde que se acontecieran-, y los ignoran los alumnos de la treintena Escuelas de Periodismo universitarias existentes a lo largo del país, pero que serán los profesionales de la información en el Siglo XXI, tan cercano a nuestros días.

\section{Estatuto Constitucional de 1970}

"Los pueblos que olvidan su historia están obligados a repetirla", afirmó el pensador norteamericano George Santayana. Creo que es válido citar aquí ese aforismo, al rememorarse documentalmente lo que acontenció en un sector de la prensa chilena durante un convulso trienio. En ése se buscó en el país implantar concretamente el socialismo. Conviene recordar que después de verificada la elección presidencial del 4 de septiembre de 1970, surgieron temores por el destino de las libertades públicas, requiriéndosele por el Gobierno del Presidente Frei Montalva y por el Partido Demócrata Cristiano a la Unidad Popular de entonces, un Estatuto de Garantía, que se incorporó a la Constitución Política del Estado, profundizándose algunas de ellas, como las de opinión e información. Dicho Estatuto fue definido más tarde por el Presidente Allende en su diálogo con el extremista francés Regis Debray como una "necesidad táctica", pues "en ese momento lo importante era tomar el mando". Esta reserva metal vino a explicar que fuera trasgredido muchas veces, dejándolo en calidad de mero dique de papel ante una planificada ofensiva marxista.

Con su texto se quiso precaver la posibilidad de la persecución de las ideas por el régimen triunfante, adhiriéndose a un pluralismo irrestricto al establecer el Artículo 10 № 3 de la Carta Fundamental, que no podía ser constitutiva de delito o abuso sustentar o difundir cualquier idea política. Este precepto, en la práctica, legitimó constitucionalmente, entre otras, las ideas totalitarias y terroristas. Por otra parte, el programa que animaba la U.P. planteaba que los medios de comunicación eran "fundamentales 
para ayudar a la formación de una nueva cultura y un hombre nuevo. Por eso se deberá imprimirles una orientación educativa y liberarlos de su carácter comercial, adoptando las medidas para que las organizaciones sociales dispongan de estos medios eliminando de ellos la presencia nefasta de los monopolios".

Durante el trienio aludido se verificó una larga e intensa lucha de la oposición y de la prensa democrática contra un oficialismo que pretendía poner en práctica su programa político amenazante de la libertad de expresión y del estado de derecho y que se concretara, con resultados disímiles, en parte. Hubo un libertinaje notorio por parte de prensa oficialista y ello dio origen a su vez a contraataques de órganos informativos de tendencia opuesta, como los que detalla el libro d 1 CEP. Todo ello descentró la libertad de expresión, sometida a partir de 1973 a muy graves anulaciones y controles, de diversa naturaleza, por el régimen militar.

¿Qué falló en el ámbito periodístico entre el 70 y el 73 y aún antes?. El honor de las personas en el ámbito legal fue desconocido respecto de figuras públicas, pocas de las cuales decidieron querellarse ante los tribunales para evitarse molestias, gastos y decepciones, esto último por la práctica negativa del indulto presidencial bajo las Administraciones Frei Moltalva y Allende. Por otra parte la ética periodística fue virtualmente inexistente, generándose una total impunidad en el rubro para los profesionales o seudoprofesionales del sector, del color que fueran. La polarización política así lo determinó.

La libertad de expresión, bien lo sabemos, resulta esencial para el ejercicio del periodismo, porque aquella también tiene límites que establece la normativa constitucional y legal, y también las cartas o códigos de ética profesional. Lo básico es que estos últimos sean dictados por las entidades gremiales para la autorregulacón del sector, y no por el Estado a través de leyes, ya que esto conlleva un intervencionismo del todo desaconsejable.

\section{Conviene al respecto formular algunas precisiones.}

\section{Colegiatura periodística}

El Art. 20 de la Declaración Universal de los Derechos Humanos de Naciones Unidas, suscrita por Chile en 1948, expresa que "nadie podrá ser obligado a pertenecer a una Asociación". Se trata por tanto de un derecho de las personas a asociarse, nunca de un deber. Ello tiene una particular connotación respecto de la colegiatura periodística obligatoria, ya que ésta, administrada por Gobiernos o cúpulas gremiales, es fuente de discriminaciones o controles políticos en el ámbito de la comunicación social y, en definitiva, contraria a la libre expresión. Desde hace muchos años la Sociedad Interamericana de Prensa (S.I.P.) a la cual pertenecen más de 1.300 medios informativos escritos de nuestro hemisferio, ha combatido la colegiatura forzosa, calificada de violatoria de las garantías constitucionales sobre libertad de expresión del pensamiento y libertad de asociación. Asimismo la Corte Interamericana de Derechos Humanos, dependiente de la OEA, determinó el 13 de Noviembre de 1985, mediante el voto unánime de sus 6 jueces, que la colegiación de periodistas "en cuanto impida el acceso de cualquier persona al uso pleno de los medios de comunicación social como vehículos para expresarse o transmitir información, es incompatible con el Art. 13 de la Convención Americana sobre Derechos Humanos". Esta data de 1969 y fue suscrita por Chile 
durante el Gobierno del Presidente Frei Montalva, y ratificada en 1990 incorporándose al derecho chileno desde su promulgación, al año siguiente, en virtud de la reforma del año 1989 al Art. 51 de la Constitución Política del Estado, de 1980.

En nuestra Carta Fundamental figuran dos preceptos claves sobre la colegiatura. El inciso $3^{\circ}$ del № 15 del Art. 19, que expresa que nadie puede ser obligado a pertenecer a una asociación, lo cual coincide con el principio de la ONU ya aludido. A su vez, el inciso $4^{\circ}$ del № 16 del Art.19 expresa "ninguna ley o disposición de autoridad pública alguna podrá exigir la afiliación a organización o entidad alguna, como requisito para desarrollar una determinada actividad o trabajo, ni la desafiliación para mantenerse en éstos. La ley determinará las profesiones que requieren grado o título universitario y las condiciones que deban cumplirse para ejercerlas". Desde 1991, como es sabido, Periodismo figura entre ellas.

A partir del 11 de Marzo del 1981, fecha de entrada en vigor de la nueva Constitución, desapareció el requisito de la afiliación obligatoria al Colegio de Periodistas de Chile, creado en 1956. Poco antes el D.L. 3261, del 7 de Febrero del mismo año 81 , dispuso que todos los Colegios Profesionales tendrían en adelante el carácter de Asociaciones Gremiales, de las que puede haber varias en cada gremio; legalizó la libre afiliación de los profesionales; traspasó a los Tribunales de Justicia la jurisdicción ética que sobre los inscritos en sus registros tenían los respectivos Colegios y derogó todas las normas que existían para dictar aranceles de honorarios, sujetos a su libre contratación desde entonces.

\section{Jurisdicción ética}

Si se analiza en perspectiva la jurisdicción de la ética periodística en Chile, tomando como base las cartas emanadas del Colegio correspondiente, de 1963 y de 1968 y del Código de 1993, es necesario subrayar que no ha tenido el carácter riguroso que debió revestir. Sea por razones políticas o por razones gremiales, no se acreditó una actitud severa y exigente con periodistas que desacreditaban la profesión. Muy pocos casos llegaron a juzgarse y menos a sancionarse, en una época en que podía promoverse hasta la cancelación del título sujeto esto último a la ratificación de la Corte Suprema de Justicia.

El traspaso a la Justicia Ordinaria, en 1981, del conocimiento de las transgresiones a la ética profesional, tampoco mejoró la situación. En materia periodística no se conocen casos en que se haya recurrido a los Tribunales sobre el punto específico. En otras palabras, si el sistema no funcionó bien hasta 1981, tampoco lo ha hecho después. Esta es una materia que en alguna forma deberá afrontarse, ya que el autocontrol - autorregulación en el rubro de la comunicación social es algo clave, manteniéndose siempre el principio correcto de la libre afiliación. Por lo demás, los Colegios en Chile nunca perdieron sus atribuciones disciplinarias, y por tal vía ha sido posible sancionar, si hubo voluntad para ello, a infractores del correcto funcionamiento profesional puesto que los miembros de una Orden deben cumplir la normativa que ella tiene, a pesar que la afiliación voluntaria permite que no se inscriban en ella elementos controvertidos o éstos se desafilien de la misma cuando hay peligro de sanción.

El vacío ético propiamente dicho ha sido llenado en parte por el desempeño del Consejo de Etica de los Medios de Comunicación Social, a partir de 1991, que sanciona 
moralmente a los órganos informativos previo debido proceso, pero no a los periodistas como personas. Respecto de éstos, ser juzgado por pares como se dice habitualmente, no garantiza la defensa del derecho a la honra de terceros cuando se ven afectados por publicaciones o teleaudiciones ultrajantes.

Ese año la Asociación Nacional de la Prensa, la Asociación de Radiodifusores de Chile y los Canales de Televisión de recepción directa, consideraron indispensable propiciar el cumplimiento de principios ético básicos a través de una instancia propia. Mas de 50 fallos han sido dictados desde entonces, tanto condenatorios como absolutorios. Esta labor contó con la plena acogida de los órganos de comunicación social escritos y audiovisuales que deben difundirlos en sus columnas o espacios. Hace un sexenio, en consecuencia, se cuenta con un organismo destinado a determinar si los medios habrían incurrido en la infracción de normas deontológicas, o sea relativas a la ética profesional, después de conocerse las denuncias de los particulares agraviados o bien actuando de oficio, obviamente contemplándose la defensa del órgano informativo objetado.

Deben aquí recordarse fallos relevantes sobre la ética del periodismo de investigación, de la publicación de encuestas -sobre todo electorales; del periodismo fotográfi$\mathrm{Co}$; del honor de las personas difuntas; de la crítica política legítima y de las grabaciones clandestinas que luego se destinaron a su difusión pública. El contraste con la lenidad o indulgencia respecto a la jurisdicción sobre periodistas como individualidades es notorio, y no puede responsabilizarse sólo a la carencia de normas legales expresas para; poner orden en un rubro tan delicado como la jurisdicción ética. Por otro lado, es ilusorio pensar que la asignatura de Etica impartida en las Escuelas Universitarias de Periodismo basta por si misma para que el futuro profesional conserve una impronta indeleble durante toda su carrera. Se puede tomar pie en la enseñanza universitaria de la disciplina, de semestre o un año lectivo, pero luego es básico el fortalecimiento del compromiso interior y personalísimo con los valores éticos, partiendo por el cultivo de las cuatro virtudes cardinales promovidas por Platón: Prudencia, Justicia, Fortaleza y Templanza, sobre las cuales ha escrito con tanta elocuencia el tratadista y académico norteamericano John Merrill. "Prudencia, -ha escrito-, da dirección a la vida moral y es la base racional intelectual para todo sistema ético". La Prudencia, cabe agregar, es natural en parte y en parte adquirida y combina el conocimiento con las disposiciones innatas, proviene en gran parte de la madurez de las experiencias de la vida, de la reflexión, de las lecturas, de las conversaciones y del estudio.

La segunda cardinal es la Fortaleza, que mantiene constantemente a la persona en la búsqueda de su objetivo: el objetivo que la Prudencia le ha ayudado a establecer para su propia vida. La Fortaleza es necesaria para que ayude al periodista a resistir las muchas tentaciones que podrían apartarlo del camino señalado por la Prudencia.

La tercera de estas virtudes es la Templanza, virtud que pide moderación razonable o una mezcla prudente del dominio de la razón con las otras tendencias de la naturaleza humana. Esta es la virtud que confiere armonía y proporción a la vida moral ; la que nos ayuda a evitar el fanatismo en la prosecución de cualquiera finalidad.

Finalmente está la Justicia, virtud que se diferencia de las otras cardinales por referirse más específicamente a las relaciones sociales del hombre. La Justicia hace que se tengan en cuenta los "merecimientos" de cada persona. Todo hombre merece consideración, pero esto no significa que cada persona tenga que ser tratada como todas las otras. Por ejemplo, la Justicia no exigirá que cada ciudadano elegido para un cargo por 
la ciudad, la provincia o la nación, reciba igual atención en la televisión, o la misma cantidad de espacio en los periódicos. Tratamiento igual simplemente no satisface los merecimientos, no implica una cobertura "justa".

\section{Ética Periodística Declinante}

El panorama mundial de la libertad de prensa dista hoy de ser alentador por el número de víctimas entre periodistas, y por anulaciones o restricciones legales variadas a través del planeta. Sin embargo la otra cara de la medalla, con gran frecuencia omitida, debe también destacarse: la declinación, o para otros, la crisis de la ética profesional. Episodios graves no faltan con serio desprestigio de la actividad periodística, esté encomendada o no a personas con grados universitarios que no garantizan la adhesión a principios básicos para el resto quehacer informativo.

El renombrado National News Council de Estados Unidos, fundado en 1973 para resolver reclamos de los afectados o del público, terminó por disolverse en 1984 por falta de cooperación de los más poderosos medios informativos. A su vez, el Código de la Sociedad Sigma Delta Chi del país del norte dispone que "los medios noticiosos no deben rendir culto a la curiosidad morbosa acerca de los pormenores del vicio y del delito", lo que por cierto no se cumplió durante el circo periodístico en torno al famoso caso del asesino norteamericano O.J. Simpson. En Gran Bretaña el Consejo de Quejas sobre la Prensa se ha visto sobrepasado por una avalancha de reclamos contra la prensa escrita por su intrusión en la privacidad de la familia real, siendo sus dictámenes generalmente no acatados por los órganos irresponsables. En Perú, el Código de Honor del Periodista expresa por su parte que ellos "se abstendrán de hacer elogios de la violencia y de producir incitación a la misma". No obstante, son numerosos los profesionales encarcelados por prestar ayuda al terrorismo que ha desangrado a esa nación.

Si se tratara de establecer los índices de mayor gravedad respecto de la ética en declive en la comunicación social del mundo, hay que radicarlos en la privacidad y el honor de las personas, ambos conectados entre si. El caso mas sórdido lo protagonizó el diario sensacionalista británico "The Sun", el cual difundió imágenes de un video falso el 8 de Mayo de 1996, que involucraban en un acto sexual a la ex Princesa Diana y a un ex oficial de caballería, James Hewitt, que estuvo vinculado a ella, mientras su ex esposo el Príncipe Carlos, quien en la autorizada opinión del historiador Paul Johnson "jamás llegará a ser rey", cometía sus propias "indiscreciones", como eufemísticamente se llama en ese país, tal como en Estados Unidos, al delito de adulterio. ${ }^{1}$ Se discurrió mucho si "The Sun", de propiedad del magnate australiano Rupert Murdoch, quien por fríos cálculos mercantiles se hizo luego ciudadano norteamericano, fue engañado por astutos timadores que le vendieron el video erótico de 80 segundos, pero la verdad es que el medio está bajo sistemático escrutinio y condena de la Comisión de Quejas sobre la Prensa por abusos perpetrados para mantener su gran circulación, 4 millones de copias al día. Por lo demás Murdoch ha estado enjuiciado por la Comisión Federal de Comunicaciones de Estados Unidos, y perdió pie político por doblegarse ante China

\footnotetext{
1 Un dia después de esta conferencia se produjo el trágico accidente automovilístico en Paris que le costó la vida a Diana Spencer y a dos de sus acompañantes, perseguidos por "paparazzis". La invasión de la privacidad de la extinta es un tema aparte, que es improcedente tratar aquí.
} 
Comunista cuando se le objetaron programas de su red asiática de televisión satelital, sobre derechos humanos.

Conviene recordar que el medio londinense debió indemnizar en 1 millón y medio de dólares al cantante Elton John en 1987, por publicar noticias falsas sobre su vida sexual.

La contención y sanciones de abusos y delitos en el ancho campo de la comunicación social, no puede, por las razones antes dichas, quedar sólo entregado al frágil marco de la ética. Queda pues el ámbito legal, el cual requiere leyes justas, tribunales independientes y debidos procesos para velar por el respeto a valores cruciales para una apropiada convivencia social. En Chile en las actuales circunstancias se entrecruzan principios la libertad, censura, restricción y suspensión en nuestro ordenamiento jurídico, lo que configura un panorama complejo y a menudo confuso.

Me referiré solo a tres aspectos de esta problemática.

\section{Defensa del Honor}

Gran parte de la polémica acerca de la futura Ley de Prensa gira sobre el articulado que contendría respecto a los delitos contra el honor. El problema se ha complicado a raíz del vigente número $4^{\circ}$ del Art. 19 de la Constitución Política del Estado, cuya derogación propuso el Senador Sergio Fernández, lo cual no es un trámite sencillo. Conviene recordar que en 1980 dicho precepto introdujo, junto con el respeto y protección a la honra de las personas, una variante del honor y a su privacidad, principios que también resguardan textos internacionales suscritos y ratificados por Chile, el concepto de respeto y protección de la vida pública. Ello es muy discutible, ya que si los funcionarios no han logrado que se les respete por sus actuaciones como tales, se clausura en el fondo el derecho a criticarlos.

Un primer intento de tipificar delitos en el rubro lo originó la Ley 18.313 del 17 de Mayo de 1984, que tuvo un rechazo generalizado. Ante la luz de fundados reparos jurídicos, el Gobierno Militar solicitó un anteproyecto de modificación a la Ley sobre Abusos de Publicidad, a cuyo texto se había integrado la desafortunada legislación. EI anteproyecto preparado por representantes de la Asociación Nacional de la Prensa, la Asociación de Radiodifusores de Chile y las Escuelas de Periodismo de la Universidad de Chile y de la Universidad Católica y en esa última condición a mi me tocó intervenir, fue rechazado de plano por el Gobierno no obstante el favorable eco nacional que produjo, pero, para verdad es el tiempo. Varios de sus artículos, claro que restablecido en 1990 el régimen democrático fueron aprovechados por la Ley 19.048 sobre Libertad de Expresión, de febrero de 1991, destinado a perfeccionar una normativa antigua.

La sobreprotección jurídica del honor y la privacidad de las personas, creándose o reflotándose antiguos tipos delictivos, concluye por privar a tales principios de un resguardo eficaz debido a que las leyes correspondientes, por su exageración, terminan por no aplicarse. Hay que conciliar la libertad de prensa, que conlleva la existencia de un interés público real por develar irregularidades perpetradas por personas de connotación pública con objetivos ejemplarizadores, con la defensa de valores de las personas cuyo atropello puede causarle daños morales y materiales irreparables. Se trata en el fondo de un asunto de prudencia y equidad legislativa que armonice ambos propósitos. Algunos estiman que la mejor Ley de Prensa es aquella que no existe, pero en el mundo 
hay muchas leyes justas en el rubro, que aplicadas por Tribunales con independencia del Poder Ejecutivo, resuelven satisfactoriamente conflictos entre particulares, o entre éstos y el Estado. La defensa del honor de las personas está en nuestro país contemplada en teoría en un sinnúmero de preceptos, pero en la práctica sus concreciones son bastante insatisfactorias. Escasa es la jurisprudencia acumulada y de muy desigual calidad, porque escasos son los pleitos que llegan a los Tribunales. Muchas víctimas de ultraje a su patrimonio moral prefieren ignorarlos por la lentitud de la administración de justicia, el costo de sus procedimientos y sus malos resultados, pero hay contadas excepciones al invocarse la Ley de Seguridad del Estado o la Legislación Militar. Ahí si que hay una expedición inusual y se explica ello por el fuero de los querellantes, pero en los pleitos comunes se necesita la tenacidad de los afectados, -caso de Enrique Lafourcade 1982-, o la concurrencia de múltiples demandantes, -casos de Martorell y de Bonvallet-, para que los jueces tomen medidas en amparo de los agraviados, que suelen terminar en benévolas remisiones de penas. Si en Chile se asiste a una desvalorización peligrosa de un bien jurídico de la trascendencia del honor, en ello lamentablemente los jueces tienen su cuota de responsabilidad.

Legislaciones draconianas tampoco solucionan este grave problema, porque con el pretexto de que la prensa, principal destinataria de aquellas, sea muy pero muy responsable, termina por no ser libre, lo cual constituye evidentemente un contrasentido constitucional.

\section{Censura y sus Alcances}

El debate sobre ella se está dando en distintos frentes, siendo el más importante la proyectada abolición de la referente al cine y a su publicidad, que adquirió rango constitucional con el Acta №3, de 1976, criterio ratificado en la Constitución de 1980. Pero estaba ya en vigencia el Decreto Ley 679 de 1974, que creó el llamado Consejo de Calificación Cinematográfica, pero en el fondo de censura, el cual hasta ahora ha podido prohibir la exhibición legal de películas conflictiva, aunque después de 1990 esta facultad ha resultado insignificante. El cine a pesar de su decreciente influencia social repercute en la televisión de audiencia masiva, porque las películas rechazadas por el Consejo del Cine no pueden ser exhibidas por los canales televisivos. En otros términos, si a ese organismo dependiente del Ministerio de Educación sólo se le permite escalafonar las películas: "Para todo espectador", "Mayores de 14" y "Mayores de 18 años", prohibiéndole impedir su exhibición pública, se abre el camino a una avalancha de pornografía, violencia, truculencia y otros desmanes perniciosos para la sociedad chilena y en particular para la juventud y la niñez, a menos que los importadores de películas sean cautelosos en su intento de introducción al pais o decidan cortar los filmes en sus partes más tenebrosas como ha sido costumbre hasta ahora.

El Consejo Nacional de Televisión, que también tiene rango constitucional a pesar de estar dividido internamente en cuanto a valores ( caso del programa "Plan Z" donde se agravió el nombre y la memoria del ex Presidente Allende) nada podrá hacer al respecto, aparte que carece de personal para evaluar posibles transgresiones al llamado correcto funcionamiento de los canales de recepción directa, por cable y pronto por satélite, además que esto último es virtualmente imposible. Sin embargo hay que distinguir entre los canales gratuitos y los de pago, pues en el segundo grupo la respon- 
sabilidad de los adquirentes del servicio, los padres de familia, será determinante para impedir que los menores presencien en sus hogares espectáculos nocivos.

La candidez legislativa y administrativa chilena alcanza caracteres notorios en este campo. Muchos creen que los inspectores cinematográficos, inexistentes, pueden expulsar de las salas a quienes tienen menos de la edad requerida para estar allí, incluso en horarios escolares. Por otra parte, otros creen que las letras "R", ( con Reservas ) o "F" ( Para ver en Familia ), propiciadas oficialmente por el Consejo Nacional de Televisión, son acatadas en los hogares chilenos. ¿Y quién puede garantizar que después de las 22 horas en todo el territorio nacional sólo los mayores de 18 años vean programas surtidos y aun publicidad selectiva, como la del tabaco y el alcohol, aptos sólo para quienes superen dicha edad?, La respuesta es clara: nadie. Existe en consecuencia una falta de control eficaz, que en Estados Unidos se trata de ejercitar a través del llamado "V" ( de violencia) Chip, para que los padres bloqueen programas televisivos inconvenientes para sus hijos, lo cual no pudo extenderse a Internet, porque como es sabido, la Corte Suprema de Estados Unidos el 26 de Junio recién pasado declaró una importante sección de la ley conocida como Acta de Defensa de las Comunicaciones, de Febrero de 1996, impulsada por el Presidente Clinton, contraria a la Primera Enmienda de la Constitución Norteamericana de 1791, o sea, la consideró inconstitucional.

La sentencia de la Corte Suprema de Chile prohibiendo definitivamente la exhibición legal de la película "La Ultima Tentación de Cristo", más allá de zanjar un antiguo diferendo, precisó que el Consejo de Calificación Cinematográfica no tiene facultades para reconsiderar dictámenes de películas anteriormente evaluadas. En este caso concreto, una presión socialista superior en el Ministerio de Educación permitió que se reviera una antigua prohibición, con el concurso de consejeros deseosos de congraciarse con el poder. Estos y otros, si subsisten en dicho Consejo, cuya legislación se reformaría luego de la reforma constitucional, debieran ser cuidadosos en evitar las consecuencias del delito de desacato.

Colindante con el tema de la censura propiamente dicha, o sea del cine y de la comunicación social global, en el caso de una hipotética guerra externa, debe añadirse el controvertido tema de las prohibiciones judiciales informativas. La Corte de Apelaciones de Valparaíso revocó hace poco una, en un bullado proceso penal sobre tráfico de drogas y lavado de dinero. El Tribunal de Alzada porteño, aparte de la decisión puntual, inició un criterio jurisprudencial valioso al sostener que el Art, 25 de la Ley sobre Abusos de Publicidad, que autoriza las prohibiciones, está derogado por la Constitución de 1980 , pero asimismo le dio carácter de censura previa a la prohibición informativa, posición pionera y relevante. La derogación de aquella ya se ha planteado como indicación a la futura Ley de Prensa, pero el problema surge cuando se produce una colisión entre el éxito de las investigaciones judiciales y la libre información. Es posible conciliar ambas fijando un corto plazo improrrogable al Juez de primera instancia, pero lo que no puede perdurar es un plazo indefinido y discrecional que hace caer una verdadera cortina de silencio sobre juicios penales relevantes. Por lo demás si existe un sumario secreto, bien podría aumentarse la pena a suspensión de cargo u oficio público en su grados medio a máximo a los funcionarios judiciales que filtren informaciones de los procesos que tramitan, como me correspondió sugerirlo a la Comisión de Constitución, Legislación y Justicia del Senado el año pasado, en un informe requerido por ella. 
Por otra parte está vigente el Art. 74 bis b) del Código de Procedimiento Penal que prohibe a Carabineros e Investigaciones proporcionar informaciones sobre las pesquisas que realiza. Hay otras normas legales y judiciales también aplicables en este rubro.

Podrá discutirse académica o jurídicamente si constituye una forma de censura la prohibición de la difusión de encuestas electorales por televisión, tres días antes de las elecciones presidenciales, parlamentarias o plebiscitos, y antes de las 18:00 hrs. del día de su verificación, según resolución del Consejo Nacional de Televisión del 10 de Marzo de 1994. Este punto volverá a recobrar actualidad respecto de las próximas elecciones parlamentarias del próximo mes de Diciembre, en particular si existen visos de inconstitucionalidad de esta decisión administrativa.

\section{Libertad de Programación en TV}

Frente a estos dos puntos abiertos a la controversia, la defensa del honor y la censura, cabe celebrar la decisión de la Corte Suprema del 22 de Agosto confirmando un fallo de la Corte de Apelaciones de Santiago, que consideró inconstitucional e ilegal la pretensión que dos canales de televisión de recepción directa, debieron transmitir los spots de una campaña estatal sobre el Sida. El Consejo Nacional de Televisión no intervino en la materia, desestimando una solicitud al respecto de parlamentarios del Partido Socialista. Luego dos dictámenes ratificaron la doctrina correcta. No debe haber interferencia alguna en la libertad de programación de las estaciones televisivas, ratificándose una jurisprudencia del máximo Tribunal de la República de 1984, que en otras circunstancias políticas y jurídicas, planteó la misma idea. Su desconocimiento vulneraría la libertad de expresión y el derecho de propiedad. Es trascendente que tanto la Corte Suprema, en este caso como en el otro anterior respecto a una película blasfema, como en su radio de acción el Tribunal Constitucional, sienten doctrina permanente en un rubro donde afloran tendencias crudamente estatistas.

Si es crucial la misión de la magistratura para interpretar la legislación atinente a la comunicación social, no menos importante es que aquella sea justa exaltando la libre expresión, pero fijando también normas estrictas de responsabilidad. Actualmente hay numerosos proyectos de ley en trámite parlamentario, que en su conjunto crearían un nuevo escenario para el sector respecto del ejercicio del periodismo y a normas sectoriales en televisión, radiodifusión, cinematografía e informática. La modernización legal en un ámbito sujeto a veloces cambios tecnológicos, no cabe duda que, es indispensable al finalizar el siglo XX, pero hay que considerar paralelamente valores sociales significativos que no deben ser erosionados o vulnerados. Si esto ocurre triunfa el libertinaje y la antiética.

"La libertad es una planta delicada", escribió el Premio Nobel de Economía Milton Friedman, académico asimismo de la Universidad de Chicago. Hay por ello que cuidarla con esmero, encuadrada en el marco del derecho y en un orden moral o ético. Lograr esta meta constituye un desafío que no puede eludirse para beneficio de Chile y los chilenos. 